www.jmscr.igmpublication.org

Impact Factor (SJIF): 6.379

Index Copernicus Value: 71.58

ISSN (e)-2347-176x ISSN (p) 2455-0450

crossref DOI: https://dx.doi.org/10.18535/jmscr/v6i3.178

Journal Of Medical Science And Clinical Research

\title{
Lipid Profile of Blood and Bile in Patients with Gall Stone Disease
}

\author{
Authors \\ Dr Harpreet Kaur, Dr Jaspreet Singh Dil, Dr Harkomal Kaur, Dr Jaspreet \\ GMC Amritsar
}

\section{Introduction}

Cholelithiasis is the commonest disease affecting the gall bladder, which is a major cause of upper abdominal emergencies ${ }^{1,2}$. Various constituents of gall stones include cholesterol, bilirubin, calcium, triglycerides, fatty acids, phospholipids and proteins $^{3,4}$. These stones may be classified as cholesterol, pigment and mixed stones ${ }^{5}$ of which mixed stones constitute the majority and pure cholesterol stones being a rarity ${ }^{6}$. Researchers have tried to understand the pathogenesis of stone formation. Super saturation and concentration of bile, crystal nucleation and gall bladder dysmotility have been implicated as aetiological factors ${ }^{7}$. Supersaturation of bile with cholesterol is found to be the most significant factor for formation of cholesterol stones ${ }^{8,9}$.

Hyperlipidemia may lead to cholesterol hypersecretion in biliary canaliculi. Relatively higher levels of cholesterol and reduced phospholipids as well as bile acids leads to nucleation of cholesterol crystals causing cholesterol stone formation ${ }^{10}$. However, high unconjugated bilirubin levels in bile is a prerequisite for pigment stone formation ${ }^{11}$.

Altered lipid metabolism with more secretion of cholesterol into bile by liver generally is considered as the pathological cause for cholesterol stones ${ }^{12}$. Various situations like female gender, oestrogen therapy, hypertriglyceridemia, obesity, diabetes, excess fat diet and genetic causes have found to be having close relationwith cholesterol stone formation ${ }^{12,13,14}$. Moreover, high levels of triglycerides (TGs) and low levels of high density lipoproteins (HDL) have been found to be consistently associated with gall stones ${ }^{15}$.

Thus, the aim of our study is to determine the levels of various lipids in serum and bile viz. cholesterol, triglycerides, HDL-cholesterol, Low Density Lipoprotein (LDL)-cholesterol, and phospholipids in patients of cholelithiasis and in control subjects and to critically analyze these estimations and to make observations as to their role in the etiopathogenesis of gallstones.

\section{Material and Methods}

The present randomized prospective observational study was conducted on a total of hundred cases which included half in the study group and the other half in the control group. The sample size was calculated in consultation with the statistician to keep power of the study more than $85 \%$.

The study group comprised of 50 adult patients of acute and/or chronic cholecystitis and cholelithiasis diagnosed on the basis of clinical picture supported by ultrasonography study. These 
patients were undertaken for cholecystectomy. The control group comprised of 50 adult patients who underwent laparotomy for diseases other than hepatobiliary disorders. These patients were included in the control group after gall stones were ruled out clinically and on ultrasound examination.

In all the cases detailed clinical history was taken and physical examination was recorded on a proforma specially prepared for this study.

Patients with obesity due to excessive intake of fats, diabetes mellitus, excessive alcohol consumption and women using oral contraceptive pills were excluded from the study as these factors alter lipid metabolism.

\section{Serum Lipidogram consisted of the following:}

S. Cholesterol

\section{Observations and Results}

Table 1 Serum Lipid Levels

\begin{tabular}{|c|c|c|c|}
\hline Serum Lipids & Study group & Control group & p- value \\
\hline S. Cholesterol & $161.54+\_47.5$ & $156+-179.36$ & $>0.10(\mathrm{NS})$ \\
\hline Phospholipids & $166.59+71.17$ & $121.06+36.72$ & $<0.01(\mathrm{~S})$ \\
\hline HDL & $40.18+12.85$ & $31.5+13.5$ & $>0.01(\mathrm{NS})$ \\
\hline LDL & $100.80+38.29$ & $66.13+68.67$ & $<0.001(\mathrm{~S})$ \\
\hline TGs & $134.98+65.68$ & $96.64+68.29$ & $<0.01(\mathrm{~S})$ \\
\hline
\end{tabular}

Table 2 Biliary Lipid Levels

\begin{tabular}{|c|c|c|c|}
\hline Biliary lipid levels & Study group & Control group & p-value \\
\hline Cholesterol & $349.42+174.60$ & $178.16+136.94$ & $<0.01(\mathrm{~S})$ \\
\hline Phospholipids & $1819.15+1040.10$ & $1753.84+1427.55$ & $>0.10(\mathrm{~S})$ \\
\hline HDL & $182.80+111.15$ & $43.06+15.25$ & $<0.01(\mathrm{~S})$ \\
\hline LDL & $129.58+103.68$ & $63.46+103.68$ & $<0.01(\mathrm{~S})$ \\
\hline TGs & $179.40+142.22$ & $327.20+295.55$ & $<0.01(\mathrm{~S})$ \\
\hline
\end{tabular}

Table 3 Serum and Biliary Lipids in Study Group

\begin{tabular}{|c|c|c|c|}
\hline Lipid values & Serum & Bile & p-value \\
\hline Cholesterol & $161.54+47.51$ & $349.42+174.60$ & $<0.01(\mathrm{~S})$ \\
\hline Phospholipids & $166.59+71.17$ & $1819.15+1040.10$ & $<0.001(\mathrm{~S})$ \\
\hline HDL & $40.18+12.85$ & $182.80+111.15$ & $<0.001(\mathrm{~S})$ \\
\hline LDL & $100.80+38.29$ & $129.58+103.68$ & $>0.10(\mathrm{NS})$ \\
\hline TGs & $134.98+65.68$ & $179.40+141.42$ & $<0.10(\mathrm{~S})$ \\
\hline
\end{tabular}

Table 4: Serum and Biliary Lipids in Control Group

\begin{tabular}{|c|c|c|c|}
\hline Lipid values & Serum & Bile & p-value \\
\hline Cholesterol & $156.78+179.36$ & $178.16+136.44$ & $>0.10(\mathrm{NS})$ \\
\hline Phospholipids & $121.06+36.72$ & $1753.84+1427.55$ & $=0.001(\mathrm{~S})$ \\
\hline HDL & $31.5+13.51$ & $43.06+15.25$ & $>0.10(\mathrm{NS})$ \\
\hline LDL & $66.13+68.67$ & $63.46+64.67$ & $>0.01(\mathrm{NS})$ \\
\hline TGs & $96.64+68.29$ & $327.20+295.55$ & $<0.01(\mathrm{~S})$ \\
\hline
\end{tabular}


The demographic profile in our study in both the groups (study as well as control) were similar and no statistical significance was found in the two groups in terms of age and sex distribution.The study included patients with ages ranging from 26-72 years of age. In the study group, 23 patients (46\%) were in the age range of 25-44 years, 21 patients $(42 \%)$ were in the age range of 45-64 years, only 6 patients $(12 \%)$ were 65 years and above. A large majority of patients 26 out of 50 $(52 \%)$ in the control group were in the age range of $25-44$ years, 18 patients $(36 \%)$ fell in the age range of 45-65 years and 5 patients (10\%) were 65 years and above. Majority of patients in the study group as well as the control group comprised of females, 34 patients $(68 \%)$ in study group and 35 patients $(71.4 \%)$ in the control group respectively. On recording the serum lipid values in the two groups, the serum cholesterol was found to be comparable and no statistical difference was found between the two groups. ( $\mathrm{p}$-value >0.01). The serum phospholipids were found to be significantly higher in the study group as compared with the control group (p-value $<0.01$ ). However, the HDL levels in the serum were found to be comparable and had no statistical difference in the study and the control group. (p-value $>0.01$ ). On recording the serum LDL and TGs levels, the result values were found to be significantly higher in the study group. ( $\mathrm{p}$ values $<0.001$ and $<0.01$ respectively).(Table 1 )

The biliary lipid profile was noted and the levels of biliary cholesterol, phospholipids, HDL, LDL were recorded and statistically analysed. The levels of biliary cholesterol, phospholipids, HDL, LDL and TGs were found to be significantly higher in the study group in comparison to the control group with no hepatobiliary disease. (pvalues<0.01). However, the levels of phospholipids in the bile were found to be comparable in both the groups. (p-value >0.01). (Table 2)

On comparing the serum lipidogram with the biliary lipid levels the values were found to be statistically significant for phospholipids levels and triglyceride levels in the sera and bile. The remaining parameters were found to be comparable on statistical analysis.

\section{Discussion}

This study describes the levels of serum and biliary lipids in patients having acute or chronic cholecystectomy as compared to those who underwent the abdominal surgeries due to causes other than hepatobiliary.

The age of the patients ranged from 26 to 75 years, with 23 patients in study group (46\%) having ages ranging from 25 to 44 years. The control group had 52\% patients in comparable age range (26 patients). In 45-64 age group, 21 patients $(42 \%)$ belonged to study group. Only 6 patients (12\%) in study group were beyond 65 years of age. This is in concordance with study by Ahi et al in April 2017 who have found this disease to be having maximum incidence between 31- 40 years ${ }^{6}$.

Majority of the patients in the study as well as control groups comprised of females $(68 \%$ and $71.4 \%$ respectively). The preponderance of gall stone disease in female gender has been well documented in literature. Role of estrogens in formation of gall stones has been experimentally proved by Scragg et $\mathrm{al}^{16}$ (ref from thesis).

Progesterone too appears to promote production of saturated bile by causing smoothmuscle relaxation and impaired gall bladder emptying. Singletary et al have demonstrated presence of estrogen and progesterone receptors in human gall bladder (ref from thesis). Studies by Pradhan et al, Jindal et al and Gaharwar et al also echo similar results as in our study with respect to sex distribution ${ }^{17,18,19}$.

The serum cholesterol levels in study group had a mean value of $161.54 \mathrm{mg} \%$ while the control group had $156.78 \mathrm{mg} \%$ which was statistically not significant. However, difference in levels of biliary cholesterol between the two groups showed statistically significant favour toward the study group, with levels of $349.42 \mathrm{mg} \%$ as compared to $178.16 \mathrm{mg} \%$ in control group.Al katean MAG et al and Nilsell et al have reported high levels of blood 
as well as biliary cholesterol in cases of gall stones $^{20,21}$. Channe N.A. et al ${ }^{22}$, Jindal et al ${ }^{18}$ and Pettite BD et $\mathrm{al}^{23}$ (20 of B) also found high total serum cholesterol levels in cholelithiasis cases. Channe N.A. et al, in their research showed that there is increase in steroid synthesis due to free cholesterol, which leads to low production of bile acids and is responsible for hypersaturation of bile with cholesterol. Jaraari et al and Shiina et al also showed significant rise in serum cholesterol levels in gall stone patients. On the contrary, Perrson et al(thesis), found decreased levels of serum cholesterol in women with cholelithisasis ${ }^{24,25,26}$.

In our study, biliary cholesterol was found to be significantly higher than serum cholesterol. These finding coincide with findings of Rubin et al, who concluded that high biliary cholesterol causes lithogenic changes in bile composition, thus leading to sludge formation and cholelithiasis ${ }^{27}$. Similarly, Cooper et al,Janowitzet et al, Helpean et al, Kern et al and Gustafsson et al concluded that high biliary levels lead to shorter nucleation time, presence of crystals in bile and increased gall stone formation. ${ }^{28,29,30,31,32}$.

Serum phospholipids levels in study group had a mean value of $166.59 \mathrm{mg} \%$ while it was found to be $121.06 \mathrm{mg} \%$ in control group. This difference was found to be statistically significant. However, differences in biliary phospholipid levels in both groups was not found to be statistically significant.

Tandon et al in their study found high serum phospholipid levels in gall stone patients ${ }^{9}$. Studies by Harpern et al as well as Jungst et al (2001) also echoed similar results. Jungst et al emphasized the role of phospholipids in viscosity of gall bladder bile $^{33,34}$.

Mean serum HDL cholesterol levels in our study group was $40.18 \mathrm{mg} \%$ and $31.5 \mathrm{mg} \%$ in control group. This difference was statistically non significant. Biliary HDL levels in study group and control group was found to be $182.80 \mathrm{mg} \%$ and $43.06 \mathrm{mg} \%$ respectively (statistically significant).

Petitti et al pointed at the relation between low HDL levels and gall stones disease ${ }^{23}$ (thesis ref).
Thornton et al stated that HDL levels are inversely proportional to bile cholesterol saturation $^{35}$. Scragg et al studied that HDL may be inhibiting liver cholesterol synthesis ${ }^{16}$ (THESIS REF). Scrobry et al concluded in their study that high serum HDL levels leads to enhanced cholesterol delivery to liver(thesis ref) ${ }^{36}$. Janowitz et al reported a positive co-relation between total bile acids and serum HDL levels in patients with rapid nucleation time ${ }^{29}$. Recently some authors like Rasheed et al (2014) have reported low HDL levels in the patients with gall stones ${ }^{37}$. On the contrary, Rao et al in 2012, have reported high serum HDL levels to be associated with gall stones $^{12}$.

Statistically significant serum HDL levels were observed in our study group mean value 100.80 $\mathrm{mg} \%$ and $66.13 \%$ in the control group. Similarly, the mean biliary LDL levels were also significantly higher in the study group (129.5 $\mathrm{mg} \%$ ) as compared to the control group (63.46\%). Pettiti et al have linked high LDL cholesterol levels with gall stone disease (thesis ref) ${ }^{23}$. Halpern et al and kern et al also found similar results $^{30,31}$.

Shiina et al (2011) reveal significant rise in cholesterol, LDL and triglyceride levels in patients with cardiac disease who developed gall stones after cardiac surgery. Ahi et al (2017) also found similar results with respect to $\mathrm{LDL}$ cholesterol( ref B) ${ }^{6,25}$

Biliary LDL levels did not show statistically significant correlation with serum LDL levels in both study and control groups in our study. Cooper et al, Rubin et al and Gustaffson et al found higher biliary LDL levels in patients having cholelithiasis, which are in concordance with our study results ${ }^{27,28,32}$.

Mean triglycerides levels in serum in our study group was $134.98 \mathrm{mg} \%$ in comparison to $96.64 \mathrm{in}$ control group. Similarly, biliary triglyceride levels in study group averaged at $179.40 \mathrm{mg} \%$ and in control group were $327.20 \mathrm{mg} \%$. These values were found to be statistically significant. These findings are in concordance with existing 
literature which reveals that high plasma triglycerides are associated with gall stone formation independent of obesity. Scragg et al, Petit et al and Harper et al echo observations similar to those in our study ${ }^{16,23,33}$. Weerakoon et al showed high serum triglyceride levels in every young patient with cholesterol gall stone as compared to pigment gall stones ${ }^{37}$. Swelt et al also showed similar results ${ }^{13}$.

High serum triglyceride levels are also revealed by other case control studies ${ }^{37,38,39}$. Hypertriglyceridemia has been found to cause hypomotility of gall bladder by lowering its sensitivity to cytokines. This may lead to cholesterol crystallization, thus forming cholesterol stones.However, author like Olokoba et al have found no association of serum triglyceride with gall stones ${ }^{42}$.

\section{Conclusion}

According to our opinion, the plasma triglyceride value may possibly be a biological marker of susceptibility to gallstone disease. Among those prone to stone formation, increased exposure to a causal factor such as diet or oral contraceptive, may result in a raised plasma triglyceride concentration together with formation of gallstones early in life.

\section{Bibliography}

1. Ahmed A, Cheung RC, Keeffe EB: Management of gallstones and their complications. Am Fam Physician 2000, 61:1673-1680

2. Dave, A. Elevated liver enzymes and the gallbladder. M.J. Ingram 2010, 18: 67-71

3. Johnston, D. E., and Kaplan, M. M., (1993). Pathogenesis and Treatment of Gallstones. N Engl J Med, 328: 412-421

4. Selvaraju, R., Raman, G. and Narayanaswamy, R. Change in serum trace elements concentration before and after removal of gallbladder with gallstone. The internet journal of gastroenterology,2009, 8: $182-191$
5. Atamanalp RS. Is there a relationship between the serum cholesterol level and the biochemical structure of gallstone in patients with cholelithiasis? IB Extended Essay. 2012;1-20

6. Ahi KS, Singh RP, Kaur H, Moudgil A. Serum Lipid profile in pre and post cholecystectomy patients.International Journal of Anatomy, Radiology and Surgery. 2017 Apr, Vol-6(2): SO01-SO06

7. Dowling RH. Review: pathogenesis of gallstones. Aliment Pharmacol Ther. 2000;14 (Suppl 2):39-47.

8. Wang DQ, Carey MC: Complete mapping of crystallization pathways during cholesterol precipitation from model bile: influence of physical-chemical variables of pathophysiologic relevance and identification of a stable liquid crystalline state in cold, dilute and hydrophilic bile salt-containing systems. J Lipid Res 1996, 37:606-630

9. Tandon RK. Current development in the pathogenesis of gallstones. Trop Gastroenterol.1990;11(3):130-39

10. Weerakoon HTW, Ranasinghe S, Navaratne A, Sivakanesan R, Galketya KB, Rosairo S. Serum lipid concentrations in patients with cholesterol and pigment gall stones. BMC Research notes 2014; 7 : 548.

11. Vítek L, Carey MC: Enterohepatic cycling of bilirubin as a cause of 'black' pigment gallstones in adult life. Eur J Clin Invest 2003, 33:799-810.

12. Rao PJ, Jarari A, Awami HE, Patil TN. Lipid profile in bile and serum of cholelithiasis patients- a comparative study. Journal of Basic Medical and Allied Sciences 2012;1:2.

13. Smelt AH: Triglycerides and gallstone formation. Clin Chim Acta 2010, 411:1625-1631.

14. Cuevas, A., Miquel, J. F., Reyes, M. S., Zanlungo, S. and Nervi, F. (2004). Diet 
as a Risk Factor for Cholesterol Gallstone Disease. J Am Coll Nutr, 23: 187-196

15. Attili AF, Capocaccia R, Carulli N, Festi D, Roda E, Barbara L, et al. Factors associated with gallstone disease in the MICOL experience. Multicenter Italian Study on Epidemiology of Cholelithiasis. Hepatology. 1997;26:809-18

16. Scragg RKR, Calvert GD, Oliver JR. Plasma lipids and insulin in gallstone disease. A case control study. Br Med. J 1984; 289 : 521-25.

17. Pradhan SB, Joshi MR, Vaidya A. prevalence of different types of gall stone in the patients with cholelithiasis at Kathmandu Medical College, Nepal. Kathmandu Univ Med J (KUMJ). 2009;7(27):268-71

18. Jindal N, Singh G, Ali I, Sali G, Reddy R. Effect of cholelithiasis and cholecystectomy on serum lipids and blood glucose parameters. Arch Int Surg. 2013;3:97-101

19. Gaharwar A. Factors favouring cholelithiasis in North Indian population. IOSR Journal of Pharmacy. 2013;3(5):0103

20. AL-Kataan MAG, Bashi AYD, Al-Khyatt MK. Some serum lipid profile and glucose levels pre- and post - cholecystectomy. JBMS. 2010;22:1.

21. Nilsell K, Angelian B, Liljequist L, Einarsson K. Biliary lipid output and bile acid kinetics cholesterol gall stone disease. Evidence for an increased hepatic secretion of cholesterol in Swedish patients. Gastroentereology 1985; 89 : 287-93

22. Channa, N. A., Khand, F., Ghanghro, A. B. and Soomro, A. M. (2010). Quantitative analysis of serum lipid profile in gallstone patients and controls. Pak. J. Anal. Environ. Chem. 11: 59-65

23. Pettiti DB, Friedman GD, Klastsky AL. Association of history of gallbladder disease with reduced concenteration of high density lipoprotein cholesterol. New Eng J Med. 1981;304:1396-98

24. Jaraari, A. M., Jagannadharar, P., Patel, T. N., Hai, A., Awamy, H. A., El-Saeity, S. O., Abdel Kafi, E. B., El-Hemri, M N., and Tayesh, M. F. Quantitative analysis of gallstones in Libyan patients. Libyan $\mathrm{J}$ Med2010, 5: 4627-4631.

25. Shiina, Y., Toyoda, T., Kawasoe, Y., Tateno, S., Shirai, T., Matsuo, K., Mizuno, Y., Ai, T. and Niwa, K. (2011). The prevalence and risk factors for cholelithiasis and asymptomatic gallstones in adults with congenital heart disease. International Journal of Cardiology, 152: 171-176

26. Persson GE, Skold SA. Thulin AJ. Physical constitution and biochemical characteristics of patients with electively diagnosed gall stone disease. Eur J Surg 1991; 157 : 473-76.

27. Rubin M, Halpern Z, Charach G, Dvir A, Antabi E, Gilal T, Lichtenberg D. Effect of lipid infusion on bile composition and lithogenicity in patients with and without cholesterol gall stones. Gut 1992; 33 : 1400-03.

28. Cooper AD. Metabolic basis of cholesterol gall stone disease. Gastroenterol Clin N Am 1991; $20: 20-46$.

29. Janowitz P, Wechsler JG, Kuhn K, Kratzer W, Tudyka J, Swobodnik W, Ditschuneit $\mathrm{H}$ : The relationship between serum lipids, nucleation time, and biliary lipids in patients with gallstones. Clin Investig 1992, 70:430-436.

30. Hepner GW, Quartfordt SH. Kinetics of cholesterol and bile acids in patients with cholesterol cholelithiasis. Gastroenterology 1975; $69:$ 318-25.

31. Kern F Jr. Effect of dietary cholesterol on cholesterol on cholesterol and bile acid homeostasis in patients with cholesterol gall stones. J Clin Invest 1994; 93 : 118694 
32. Gustafsson U, Wang FH, Axelson M, Kallner A, Sahlin S, Einarsson K. The effect of vitamin $\mathrm{C}$ in high doses on plasma and biliary lipid composition in patients with cholesterol gall stones; prologation of the nucleation time. Eur $\mathbf{J}$ Clin Invest 1997; 27(5) : 387-91

33. Halpern Z, Rubin M, Harach G, Grotto I, Moser A, Duir A, et al . Bile and plasma lipid composition in non obese normolipidemic subjects with and without cholesterol gall stones. Liver 1993; 13 : 246-52.

34. Jungst D, Niemeyjer A, Muller I, Zundt B, Meyer G, Wilhelmi M, et al. Mucin and phospholipids determine viscosity of gall bladder bile in patients with gall stones. World. J Gastroenterology 2001; 7(2) : 203-07.

35. Thornton JR, Heaton KW, Macfarlene DG. A relation between high density lipoprotein cholesterol and bile cholesterol saturation. Br Med J 1981; 283 : 1352-54.

36. Scobey MW, Johnson FP, Rudell L. Plasma HDL cholesterol concentrations are correlated to bile cholesterol saturation indexed in African green monkey. Am J Med Sci 1991; $301: 97-101$.

37. Jørgensen T: Gallstones and plasma lipids in a Danish population. Scand $\mathrm{J}$ Gastroenterol 1989, 24:916-922

38. Thijs C, Knipschild P, Brombacher P: Serum lipids and gallstones: a case-control study. Gastroenterology 1990, 99:843-849

39. Saraya A, Irshad M, Gandhi BM, Tandon RK: Plasma lipid profile in gallstone patients from North India. Trop Gastroenterol 1995, 16:16-21

40. Jonkers IJ, Smelt AH, Ledeboer M, Hollum ME, Biemond I, Kuipers F, Stellaard F, Boverho FR, Meinders AE, Lamers $\mathrm{CH}$, Masclee AA: Gall bladder dysmotility: a risk factor for gall stone formation in hypertriglyceridaemia and reversal on triglyceride lowering therapy by bezafibrate and fish oil. Gut 2003, 52:109-115

41. Wang HH, Portincasa P, Liu M, Tso P, Samuelson LC, Wang DQ: Effect of gallbladder hypomotility on cholesterol crystallization and growth in CCKdeficient mice. Biochim Biophys Acta 2010, 1801:138-146.

42. Olokoba, A. B., Bojuwoye, B. J., Olokoba, 1. b., Braimoh, K. T., Inikori, A. K., and Abdulkareem, A. A., (2009). Relationship between gallstone disease and liver enzymes. Research journal of medical science, 3: 1-3. 